Original Research Article

\title{
Assessment of quality of life in patients on antiepileptic drugs: a hospital based cross sectional study
}

\author{
Junaid A. Ahangar ${ }^{1 *}$, Samina Farhat $^{2}$, Rabbanie T. Wani ${ }^{3}$
}

\begin{abstract}
${ }^{1}$ Department of Clinical
Pharmacology, Sher-i-Kashmir Institute of Medical Sciences (SKIMS), Soura, Jammu and Kashmir, India

${ }^{2}$ Department of Pharmacology, ${ }^{3}$ Department of Social and Preventive Medicine, Government Medical College, Srinagar, Jammu and Kashmir, India
\end{abstract}

Received: 30 May 2019

Revised: 04 June 2019

Accepted: 10 June 2019

*Correspondence to:

Dr. Junaid A. Ahangar, Email: drjunaidahangar@ gmail.com

Copyright: (C) the author(s), publisher and licensee Medip Academy. This is an openaccess article distributed under the terms of the Creative Commons Attribution NonCommercial License, which permits unrestricted noncommercial use, distribution, and reproduction in any medium, provided the original work is properly cited.

\begin{abstract}
Background: Quality of life (QOL) is a broad, multidimensional concept that usually includes subjective evaluations of both positive and negative aspects of life. Very few studies have been carried out on QOLIE 31 in India and research in this area will identify factors affecting QOL. study was therefore conducted to determine the level of health related QOL of patients of epilepsy in a tertiary care teaching hospital. To evaluate patterns of the use of anti-epileptic drugs (AEDs) and their impact on the Quality of Life (QOL) in patients with epilepsy.

Methods: The study was a hospital based cross sectional study conducted by the Department of Pharmacology in association with the Department of Medicine, Government Medical College, Srinagar. A total number of 134 patients, aged $>18$ years were studied for a period of one and a half years, January 2015-July 2016. QOLIE-31 questionnaire was used for collecting data on health-related QOL.

Results: The mean overall QOLIE-31 score was 53 corresponding to a t-score of 44. Amongst the QOLIE-31 subscales, the highest mean score was the cognitive subscale (73.6) followed by medication effects (55.5) and social functions (52).

Conclusions: It is evident from our study that there are many factors that influence QOL of people with epilepsy. Among them, type of drug therapy plays an important role. Adding clinical counselling and other interventions to address the physical, mental, psychological, social, and emotional aspects of health wellbeing is likely to achieve better health outcomes for epilepsy patients.
\end{abstract}

Keywords: Antiepileptics, Cognitive, Epilepsy

\section{INTRODUCTION}

Classifying epilepsy as a neurological disorder is inadequate, since it is also a disorder with negative social consequences. ${ }^{1}$ To an affected person, the burdens of epilepsy include physical hazards from unpredictable seizures, but also social exclusion as a result of negative attitudes towards people with epilepsy (PWE). ${ }^{2}$ Stigma may even preclude adults from marrying or PWE can be denied employment even when seizures would not render their work unsuitable or unsafe. ${ }^{3}$ Although $75-85 \%$ of PWE's in developed countries reach seizure control through individually tailored antiepileptic drug (AED) therapy, up to $25 \%$ of all patients suffer from refractory 
forms of epilepsy. ${ }^{4}$ Hence the disease may prevent those PWE from living a completely self-reliant life. ${ }^{5}$

In the last two decades, the number of research articles that focus on epilepsy as a disease associated with psychological consequences like anxiety, depression or low self-esteem has increased and demonstrated the detrimental impact of epilepsy on the individuals' healthrelated quality of life (HRQoL). ${ }^{6}$ Quality of life (QOL) is a broad, multidimensional concept that usually includes subjective evaluations of both positive and negative aspects of life. ${ }^{7}$ The concept of health-related quality of life (HRQoL) and its determinants encompass the aspects that can be clearly shown to affect health- either physical or mental. On the individual level they include physical and mental health perceptions and their correlates, notably health risks and conditions, functional status, social support, and socioeconomic status.

Quality of life (QOL) is worse in epileptic patients than in the general population, it is comparable or worse in patients with epilepsy than that in patients with other chronic conditions; and it is similar to that of healthy persons when patients with epilepsy are well-controlled. ${ }^{8}$ QOL of patients with epilepsy depends upon effectiveness of antiepileptic therapy and disease duration. Frequency of seizures seems to be one of the most relevant determinants of poor quality-of-life scores. ${ }^{9}$

People with epilepsy have been shown to report a poor QOL because they are more likely to have poor self-esteem and a high level of anxiety and depression. In some patients, the social stigma and impact on QOL can pose a greater challenge than the clinical severity Health-related quality of life (HRQOL) is recognized as an important outcome in epilepsy treatment. Research assessing the QOL associated with successful treatment of epilepsy is far behind that of other chronic conditions such as cancer, diabetes, and cardiovascular disease. Very few studies have been carried out on QOLIE-31 in India and research in this area will identify factors affecting QOL and may lead to strategies that improve the management of patients with epilepsy.

The importance of assessing psychological well-being and quality of life of individuals with epilepsy, especially in developing countries has traditionally been ignored. In recent years, assessing quality of life with chronic illnesses has become an important concern. Quality of life can be assessed by generic or disease specific measures. Generic measures assess function, disability, and distress resulting from general ill health and their main advantage is that these measures permit comparisons across illnesses, disease severity and with healthy population. However, generic measures are insensitive to the specific problems associated with each disease. Recently, a number of disease specific measures have been developed for epilepsy. Studies examining quality of life of patients with epilepsy generally reveal that they have impaired quality of life. Patients with epilepsy have relatively more compromised quality of life in the psychological, social and school domains compared to those with asthma, suggesting that these problems are specific to epilepsy and not simply the result of living with a chronic condition. It has been proved that patients with epilepsy experience significant restriction of activities leading to lower quality of life. Quality of life is an especially important health outcome to assess in patients with epilepsy. Despite its importance, there is relative lack of research on quality of life among patients with epilepsy. ${ }^{10-11}$ This study was therefore conducted to determine the level of health-related QOL of patients of epilepsy in a tertiary care teaching hospital. Objective of this study was to evaluate patterns of the use of anti-epileptic drugs (AEDs) and their impact on the Quality of Life (QOL) in patients with epilepsy.

\section{METHODS}

After getting approval from the Institutional Ethics Committee, the study was conducted by the Department of Pharmacology in association with the Department of Medicine, Government Medical College, Srinagar. The patients coming to the Neurology Department, SMHS Hospital were studied. The participants were provided with explicit explanation for their inclusion in the Study by instituting Written Informed Consent, duly translated in local Vernacular. It was a cross-sectional, observational study for a period of one and a half year.

\section{Inclusion criteria}

All patients with seizures of either sex or age group ( $>18$ years of age) who were prescribed anti-epileptic drugs were included in the study.

\section{Exclusion criteria}

- Patients who were unable to co-operate.

- Patients with inability to give consent.

- Patients treated with traditional medicines alone.

- Drug over-dose (deliberate or unintentional).

- Cases of relapse due to non-compliance.

- Patients with status epilepticus and seizures associated with acute conditions like stroke or other illnesses like hypertension, diabetes, chronic pulmonary obstructive disease, etc.

After reading the basic demographic profile, following information was collected from them (patients or their guardians); duration of illness, number of previous hospitalizations, type of epilepsy, severity of illness, current anti-epileptic treatment, number of drugs, drugs names, dose at the time of the visit, duration of present treatment and the reason for initiating current treatment (first episode, drug substitution). A total number of 134 patients were studied.

The study was conducted for a period of one and a half years, from January 2015 to July 2016. 
Quality of life in epilepsy (QOLIE-31) is a 31 item selfadministered questionnaire specifically designed to measure quality of life of people with epilepsy derived from the QOLIE-89. The QOLIE-31 has seven of the 17 QOLIE-89 subscales. The QOLIE-31 measures health related quality of life across seven domains such as seizure worry, overall quality of life, emotional wellbeing, energyfatigue, cognitive functioning, medication effects, and social functioning. Responses are summed to supply subscale scores and a total score, with higher scores indicative of better functioning. The QOLIE-31 has demonstrated good psychometric properties with internal consistency reported as Cronbach's $\mathrm{a}=0.85$ and test-retest reliability of $r=0.85$.

Data was entered in Microsoft Excel. Continuous data was summarized as mean \pm standard deviation or the five number summary as appropriate. Categorical variables were summarized as percentages. Chi-square test was used to test for independence of two categorical variables. Bar charts and pie charts were used for graphical presentation of data.

\section{RESULTS}

The mean age of the study population was 36.6 years and $64.9 \%$ of them were males and rest of them were females. Idiopathic generalized epilepsy $(41 \%)$ and simple febrile seizures $(22.4 \%)$ were the most common diagnoses.

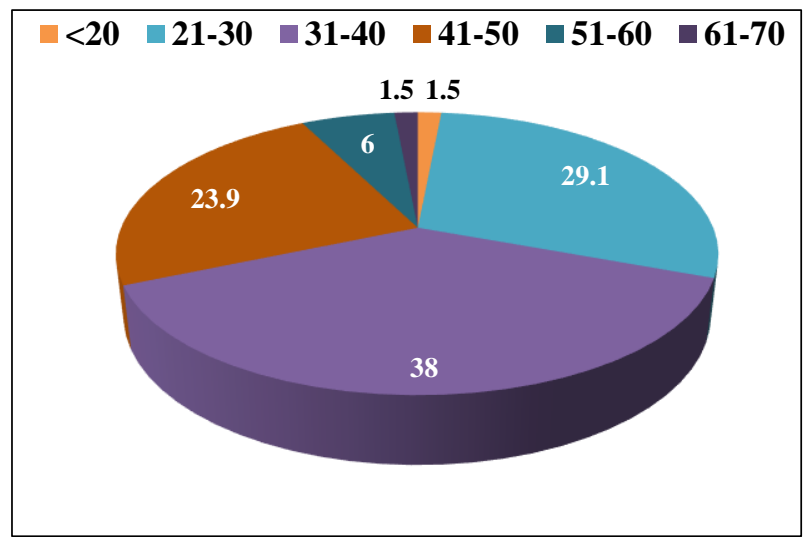

Figure 1: Distribution of the study population according to age.

Phenytoin, valproate and carbamazepine were the most common drugs prescribed to the extent of $31.3 \%, 23.1 \%$ and $14.2 \%$ respectively. The mean age of the study population was 36.6 years and $64.9 \%$ of them were males and rest of them were females (Figure 2). Idiopathic generalized epilepsy (41\%) and simple febrile seizures (22.4\%) were the most common diagnoses. Phenytoin, valproate and carbamazepine were the most common drugs prescribed to the extent of $31.3 \%, 23.1 \%$ and $14.2 \%$ respectively.

Figure 3 shows the distribution of the study population according to their residence. Eighty four $(62.7 \%)$ patients resided in rural areas and fifty (37.3\%) were from urban areas.

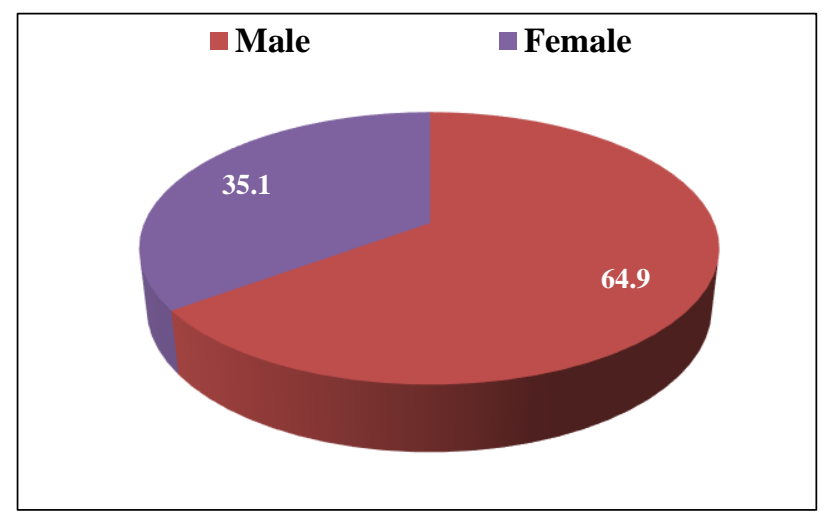

Figure 2: Distribution of the study population according to sex.

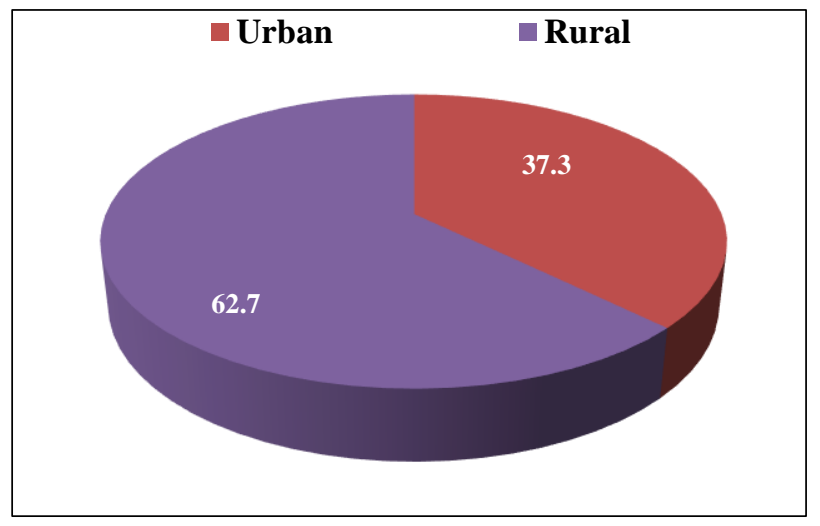

Figure 3: Distribution of study population according to residence.

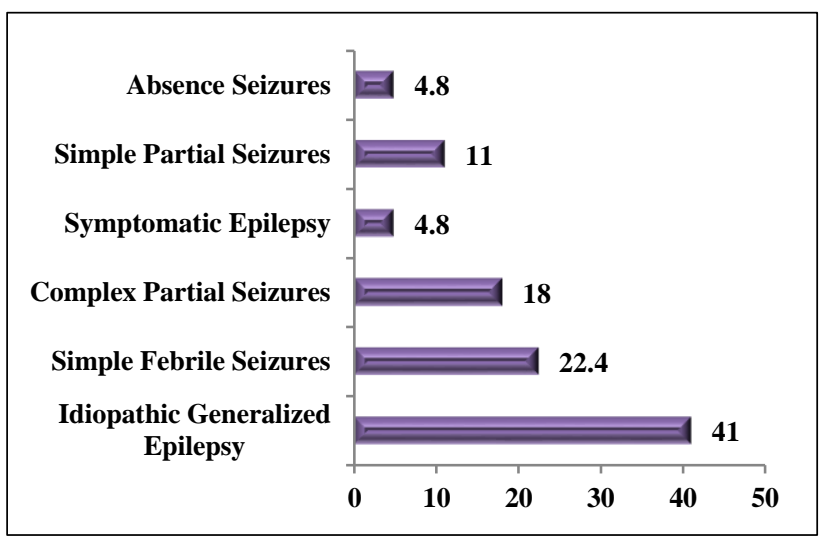

Figure 4: Distribution of study population according to diagnosis.

Figure 4 shows the distribution of the study population according to the diagnosis. Idiopathic generalized epilepsy (41\%) followed by simple febrile seizures $(22.4 \%)$ and complex partial seizures $(18 \%)$, were the three most common diagnoses in our study. Other seizure types 
included symptomatic epilepsy $(4.8 \%)$, simple partial seizures $(11 \%)$ and absence seizures $(4.8 \%)$.

The most frequently prescribed drugs to the study population were phenytoin $(31.3 \%)$, valproate $(23.1 \%)$ and carbamazepine (14.1\%). The other drugs prescribed to the study population included clobazam (6\%), oxcarbazepine $(5.2 \%)$, leviteracetam $(3.7 \%)$, phenobarbitone $(3 \%)$, lamotrigine $(3 \%)$, topiramate $(3 \%)$ and gabapentin $(0.7 \%)$. The drug combinations prescribed to the study population included valproate plus lamotrigine $(1.5 \%)$, valproate plus topiramate $(1.5 \%)$, phenytoin plus lamotrigine $(1.5 \%)$, carbamazepine plus leviteracetam $(1.5 \%)$ and phenytoin plus gabapentin (0.7\%) (Figure 5).

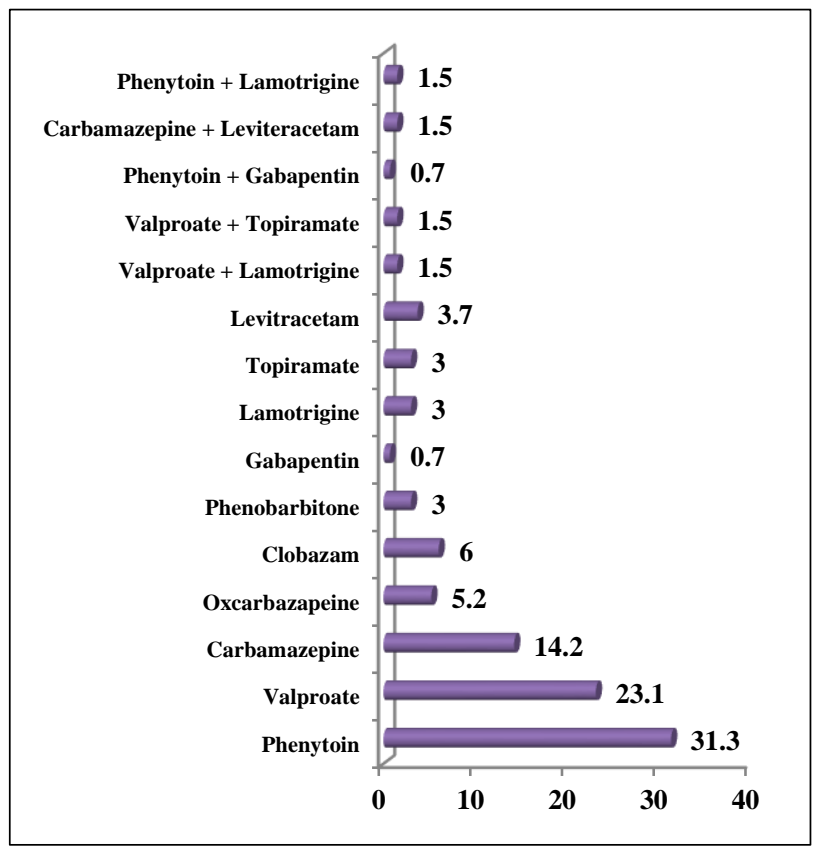

Figure 5: Antiepileptic drugs used in study population.

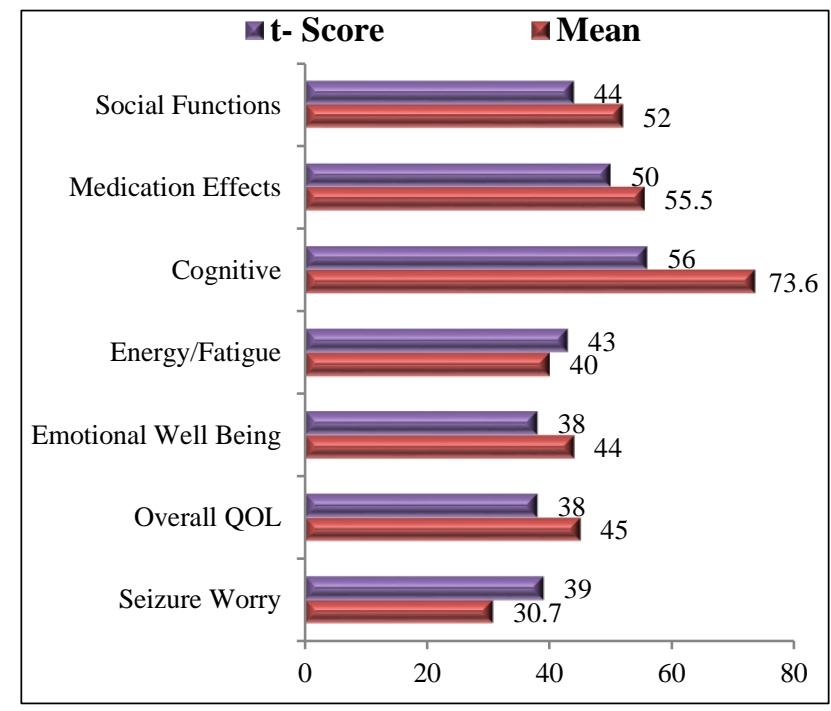

Figure 6: Total score of QOLIE-31 subscales.
The mean overall QOLIE-31 score was 53 corresponding to a t-score of 44. Amongst the QOLIE-31 subscales, the highest mean score was the cognitive subscale (73.6) followed by medication effects (55.5) and social functions (52). The other mean subscale scores included overall QOL (45), emotional wellbeing (44), energy fatigue (40) and seizure worry (30.7) (Figure 6).

\section{DISCUSSION}

Most of the study participants were in the young and middle age groups (21-50 years) with a mean age of 36.6 years ( $\mathrm{SD} \pm 10.07$ years). The male-female ratio was 1.9 .

Idiopathic generalized epilepsy (41\%) followed by simple febrile seizures $(22.4 \%)$ and complex partial seizures $(18 \%)$, were the three most common diagnoses in our study. Other seizure types included symptomatic epilepsy $(4.8 \%)$, simple partial seizures $(11 \%)$ and absence seizures $(4.8 \%)$. Similar findings have been reported by Shobhana Mathur et al. ${ }^{12}$

The most frequently prescribed drugs to the study population were phenytoin $(31.3 \%)$, valproate $(23.1 \%)$ and carbamazepine (14.1\%). Similar observations have been reported by Shobhana Mathur et al. ${ }^{12}$ Also similar results have been reported by other studies also. ${ }^{13-15}$ This shows that the pattern of pharmacological therapy for epilepsy in these studies was similar to our study.

The mean overall QOLIE-31 score was 53 corresponding to a ' $t$ ' score of 44. Amongst the QOLIE-31 subscales the highest mean score was the cognitive subscale (73.6) followed by medication effects (55.5) and social functions (52). The other mean subscale scores included Overall QOL (45), emotional wellbeing (44), energy fatigue (40) with seizure worry (30.7) being the lowest overall.

The mean total score of QOLIE-31 in this study, was almost similar to studies conducted in India but higher than studies conducted in Australia (52.9), Africa (52.1). ${ }^{16-}$ 19 A study in Malaysia has reported a higher mean total score of QOLIE-31 (68.9). ${ }^{20}$ Even though the majority of the studies had used QOLIE-31 questionnaire (different translations), different study methodologies with different inclusion and exclusion criteria would have accounted for the different scores. Higher score as reported in this study reflects a better standard of medical care.

The pattern of scores of QOLIE-31 subscales of our study was partially similar to the studies conducted in Africa and Malaysia. ${ }^{19,20}$ In our study, the emotional well-being subscale was highest, and seizure worry the lowest. The difference in pattern may be due to the reason that different countries have dissimilarities of beliefs, culture, and socioeconomic factors which in turn can affect QOL measures, thus findings from other countries, may not be relevant to the local situation. Baker et al, reported that seizure frequency was the most important clinical 
predictor of psycho-social dysfunction and emotional maladjustment. $^{21}$

Longer duration of epilepsy has been reported as predictor for poor QOL due to greater complications and disabilities. Our study found no significant association between duration of epilepsy and QOL. The probable reason may be small sample size in the present study.

A limitation of this study is the insufficient number of patients recruited. Much larger studies are required to adequately assess the Quality of Life in such patients.

\section{CONCLUSION}

It is evident from our study that there are many factors that influence QOL of people with epilepsy. Among them, type of drug therapy plays an important role. Adding clinical counselling and other interventions to address the physical, mental, psychological, social, and emotional aspects of health well-being is likely to achieve better health outcomes for epilepsy patients. Raising awareness in society regarding the existence of effective therapy through public educational campaigns might help in eliminating the stigma of epilepsy and may improve QOL of epilepsy patients. Our study findings emphasize the importance of more effective treatment of epilepsy and continuing education of the public about the nature and implications of the condition.

The findings also emphasize the importance of empowering people with epilepsy so that they are better able to accommodate their condition and to maximize the quality of their lives with the help of psychological interventions, rehabilitation and educational programs. We need to challenge the current social construction of epilepsy as a disability and stigma and aim to reduce existing treatment gaps. People with epilepsy deserve well-formulated legislative support. These measures will help the epileptic patients to become self-reliant. Finally, we need to champion a better resourced research agenda into the social realities of epilepsy, and the ways by which, these can be improved.

Funding: No funding sources

Conflict of interest: None declared

Ethical approval: The study was approved by the Institutional Ethics Committee

\section{REFERENCES}

1. De Boer HM, Mula M, Sander JW. The global burden and stigma of epilepsy. Epilepsy Behav. 2008;12(4):540-6.

2. International League Against Epilepsy Quality of life: general considerations. Epilepsia. 2003;44 (Suppl. 6):58-158.

3. Forsgren I, Beghi E, Ekman M. Cost of epilepsy in Europe. Eur J Neurol. 2005;12(Suppl 1):54-8.
4. Espie CA, Watkins J, Duncan R, Sterrick M, Mcdonach E, Espie A, et al. Perspectives on epilepsy in people with intellectual disabilities: comparison of family carer, staff carer and clinician score profiles on the Glasgow Epilepsy Outcome Scale (GEOS). Seizure. 2003;12(4):195-202.

5. Cramer JA. Quality of life and compliance. In M. R. Trimble \& W. E. Dodson (Eds.), Epilepsy and quality of life. New York, NY, US: Raven Press; 1994:49-63.

6. The WHOQOL Group. The World Health Organization Quality of Life Assessment (WHOQOL): development and psychometric properties. Soc Sci Med. 1998;46(12):1569-85.

7. Centers for Disease Control and Prevention. Measuring Healthy Days: Population assessment of health-related quality of life. Atlanta, Georgia: CDC. 2000. Available at: https://www.cdc.gov/hrqol/pdfs/mhd.pdf. Accessed on Nov 2000.

8. Nabukenya AM, Matovu JK, Wabwire-Mangen F, Wanyenze RK, Makumbi F. Health-related quality of life in epilepsy patients receiving anti-epileptic drugs at National Referral Hospitals in Uganda: a crosssectional study. Health Quality Life Outcomes. 2014;12(1):12-49.

9. Mahrer-Imhof R, Jaggi S, Bonomo A, Hediger $\mathrm{H}$, Eggenschwiler P, Krämer G, et al. Quality of life in adult patients with epilepsy and their family members. Seizure. 2013 Mar 1;22(2):128-35.

10. Thomas SV, Koshy S, Nair CS, Sarma SP. Frequent seizures and polytherapy can impair quality of life in persons with epilepsy. Neurol India. 2005 Jan 1;53(1):46-50.

11. Tedrus GM, Fonseca LC, Carvalho RM. Epilepsy and quality of life: socio-demographic and clinical aspects, and psychiatric co-morbidity. Arquivos de neuropsiquiatria. 2013 Jun;71(6):385-91.

12. Mathur S, Sen S, Ramesh L, Kumar SM. Utilization pattern of antiepileptic drugs and their adverse effects, in a teaching hospital. Asian J Pharm Clin Res. 2010 Jan;3(1):55-9.

13. Anderson M, Egunsola O, Cherrill J, Millward C, Fakis A, Choonara I. A prospective study of adverse drug reactions to antiepileptic drugs in children. BMJ open. 2015 May 1;5(6):e008298.

14. Ramakrishna P, Barman AK, Mahanta ML, Ramaiah M. Collection, Detection, Assessment, Monitoring and Prevention of Adverse Drug Reactions in the Nephrology Department of Gauhati Medical College and Hospital, Assam, India. Global J Med Res. 2014 Jun 13;5(8):653-57.

15. Jayalekshmi K, Palanisamy K, Sambathkumar Ramanathan SA. A Study on the Adverse Drug Reactions Induced by Anti-Epileptic Drugs in the Epileptic Patients. J Applied Pharmaceut Sci. 2016;6(05):119-23.

16. Pimpalkhute SA, Bajait CS, Dakhale GN, Sontakke SD, Jaiswal KM, Kinge P. Assessment of quality of life in epilepsy patients receiving anti-epileptic drugs 
in a tertiary care teaching hospital. Indian J Pharmacol. 2015;47(5):551-4.

17. Sawant N, Kinra V. An Indian study on perceptions of patients of epilepsy and their family to stigma and its impact on quality of life. Am J Clin Neurol Neurosurgery. 2015;1(1):1-9.

18. McLaughlin DP, Pachana NA, Mcfarland K. Stigma, seizure frequency and quality of life: the impact of epilepsy in late adulthood. Seizure. 2008;17(3):281-7.

19. Nubukpo P, Clément JP, Houinato D, Radji A, Grunitzky EK, Avodé G, et al. Psychosocial issues in people with epilepsy in Togo and Benin (West Africa) II: Quality of life measured using the QOLIE 31 scale. Epilepsy Behav. 2004;5(5):728-34.
20. Norsa'adah B, Zainab J, Knight A. The quality of life of people with epilepsy at a tertiary referral centre in Malaysia. Health and quality of life outcomes. 2013;11(1):143.

21. Baker GA, Jacoby A, Buck D, Stalgis C, Monnet D. Quality of life of people with epilepsy: A European study. Epilepsia. 1997;38(3):353-62.

Cite this article as: Ahangar JA, Farhat S, Wani RT. Assessment of quality of life in patients on antiepileptic drugs: a hospital based cross sectional study. Int J Basic Clin Pharmacol 2019;8:1532-7. 